\title{
Value-In-Context with Service Innovation in the Digital Age: A Service-Dominant Logic Perspective
}

\author{
Martin Mikusz \\ University of Stuttgart \\ martin.mikusz@gsame.uni-stuttgart.de
}

\begin{abstract}
The increasingly complex service context with the convergence of physical products, digitalization, and service offerings presents a major challenge for IS research on service innovation. This article addresses the resulting need for research on an adequate understanding of the perceived value of innovative digital services. It continues previous work that makes the first move in this regard-conceptualizing this value as the sum of direct value-in-context ( $S$-D logic), and indirect and option value-in-context (both newly introduced). This article closes two research gaps. First, the option and indirect value-in-context components are clarified by developing propositions that link both to $S$-D logic's main concepts of service innovation. Second, the value-in-context anatomy is empirically validated with two conjoint analyses. It can be shown that both newly introduced components of value-in-context indeed are decisive factors for customers' perceptions of value with innovative digital services-implicating their conceptual separation.
\end{abstract}

\section{Introduction}

A defining characteristic of pervasive digital technology is the integration of digital capabilities into products that previously had a purely physical materiality (e.g. cars). The uniquely powerful affordances of digital technology allow expanding the existing physical materiality by entangling it with software-based capabilities [1], and connecting the now digitized, intelligent product with the environment.

The convergence of physical products and digitalization on the one hand, and physical products and service offerings on the other, unfolds an interactive effect [2] —or in other words, "the service revolution and the information revolution are two sides of the same coin" [3]. The resulting digitized products are henceforth platforms for service provision where certain product functions exist outside the physical device in a product cloud. In this way, the traditional role of the service function is expanded and enables novel, platform-based and highly integrated offerings $[4,5,6]$.

The convergence of physical products, digitalization, and service offerings heightens the need for a shift to service oriented thinking [6], as promoted by, e.g., Service-Dominant logic (S-D logic). The resulting increasingly complex service context presents a major challenge for service innovation research. Ostrom et al. [7] identify three critical contextual factors that lead to future research directions:

First, service innovation is increasingly taking place within ecosystems that are enabled by service platforms. This organizational context requires a new understanding of value and value creation [7]. The generative capacity of digitized products (as service platforms) offers unanticipated opportunities for innovation that overstep the boundaries of the physical product [2]. Thus, understanding of innovation should focus on the value experienced by the customer rather than on the output delivered by a service provider [6].

Second, the technological context in which service innovation takes place is rapidly changing. The "ubiquitous, always on, always connected, smart, and global world" [7] represents a radically new context for co-creating and experiencing service [7]. A single digitized product (as service platform) provides multiple new affordances, each of which previously required an extra product. Hence, it brings previously separate user experiences together [1] and has fluid product boundaries depending on the use context.

Third, as digitized products enable omnipresent communication and interaction [8], external entities and especially customers are increasingly involved in service innovation (e.g. open innovation or crowdsourcing). This opens up opportunities for more personalized, higher quality services, and deeper customer relationships [7].

This article addresses the abovementioned need for research on an adequate understanding of value experienced by the customer with service innovation in the digital age. It is necessary to conceptualize this value on the consequence level rather than on the attribute 
level when studying service innovation in the digital age [9]. The consequence level refers to the subjective experience resulting from the use of an offering, e.g. greater quality or customization. The attribute level refers to physical characteristics of an offering $[10,11]$. To briefly illustrate the difference, this work draws on one of the capabilities of smart products, namely their capability to communicate and cooperate with other objects [12]. It has no value for the user per se. Instead, value stems from affordances of this attributecooperatively brought out services like multi-modal routing (consequence level).

Mikusz [13] and Mikusz and Herter [9] propose to conceptualize value in this sense applying S-D logic, and especially S-D logic's understanding of value as value-in-context. In essence, value-in-context describes (at the consequence level) the subjective experience resulting from the use of an offering in a particular context (see in more detail in chapter 2). However, the authors argue that innovative digital services require a more differentiated anatomy of value-in-context. They propose to split value-in-context into three components that may be added- - direct value-in-context", "indirect value-in-context", and "option value-in-context". Direct value-in-context equals S-D logic's understanding of value-in-context [e.g. 6, 14, 15]. The authors newly introduce the two other value-in-context components on the assumption that both are also decisive factors in customers' perceptions of value and so substantially contribute to service experience. Following this, both components should be conceptually separated in order to increase understanding of the perceived value of innovative digital services and reveal potentials for service innovation in the digital age.

This article continues the work presented in [9] and [13] closing two research gaps: First, the anatomy of value-in-context presented in [9] and [13] is inspired by and conceptually rooted in an anatomy of value related to ecosystem services (i.e. services provided by the ecosystem to society such as recreation) presented in [16]. ${ }^{1}$ In this article, the newly introduced option and indirect value-in-context components are clarified by developing propositions that link both to S-D logic's understanding of service innovation. Propositions are specific subsets of statements in a discipline that link its concepts [17]. Second, it is examined if indirect and option value-in-context indeed are perceived decisive factors from the viewpoint of customers and thus substantially contribute to the value experienced by

\footnotetext{
${ }^{1}$ Hein et al. [16] define four value types that stakeholders attribute to ecosystem services: (1) Indirect use values stem from the indirect utilization of ecosystems, in particular through positive externalities that occur when the consumption or production of a service causes (also) a benefit to a third party. (2) Option values arise as consumers are unsure about their future demand for a service. So they are
}

customers with innovative digital services-implicating a conceptual separation.

The above leads to the following research questions:

RQ1: How are the option and indirect value-incontext components linked to the main concepts of service innovation from the perspective of S-D logic?

RQ2: How far are the option and indirect value-incontext components decisive factors for customers' perceptions of the overall value-in-context?

By answering the research questions, this article advances the anatomy of value-in-context on both a conceptual and empirical level. It makes the next step towards a more detailed and differentiated understanding of value (in-context) with innovative digital services. Beyond service research, value conceptualizations at the consequence level matter a lot to IS research as the recently increased focus on generativity [18] and affordance theory [19] indicate. All these approaches point in the same direction.

The work at hand combines conceptual and empirical research. Chapter 2 introduces the S-D logic perspective on value creation in the digital age, including the anatomy value-in-context (henceforth most often abbreviated as v-i-c) that this article aims to advance. This is done on the conceptual level deriving the propositions presented in chapter 3 (RQ1), and on the empirical level with two conjoint analyses conducted in order to answer RQ2 in chapter 4 (chapter 4 provides detailed insights into method and operationalization). Chapter 5 concludes with implications for practice and IS research on digitally enabled service innovation, limitations of the research presented here, and avenues for further research.

\section{S-D Logic Perspective on Value Creation in the Digital Age}

S-D logic involves a new perspective on value creation $[14,15,20]$. Service is not an intangible product, i.e. a unit of output, but the common denominator of economic and social exchange [21]. From this perspective, service provision is a joint and reciprocal value creation process in which different actors-labeled as resource integrators - use a number of different resources to support the value-adding process of the customer. In this collaborative and interactive process, the distinction between producer and customer dissolves and leads to value co-creation

willing to pay to keep open the option of using a resource in the future. The total use value equals the sum of (1) indirect use and (2) option values, as well as the (3) direct use value that arises from direct utilization of ecosystems services, and (4) none-use value, which is not relevant here. 
where also the customer is a co-creator of value. All actors form a value co-creation network [15, 22] that $\mathrm{S}$ $\mathrm{D}$ logic scholars have recently embedded into a superior structure - the service ecosystem $[20,23]{ }^{2}$

S-D logic refers to two distinct types of resourcesoperand and operant. Operand resources are usually tangible and static resources that require some action to make them valuable, e.g. a vehicle. Operant resources on the other hand are usually intangible and dynamic resources that are capable of acting on operand and other operant resources, e.g. knowledge. According to S-D logic, value can result only from the application of operant resources that may be directly transmitted or through operand resources [21]. This means when physical goods are involved, they are understood as mechanisms for service provision.

The resulting value for the customer is fundamentally derived in use-labeled as value-inuse - and determined contingent upon the concrete context of use-labeled as value-in-context (v-i-c) [15, 23, 24]. This means that a firm's offering is not embedded with value (attribute level; value-inexchange). Instead, value only occurs when the offering is useful to the customer (consequence level; value-inuse) in a certain context. Hence, value manifests when the customer integrates the offering in his value adding process as the context of use (consequence level; v-i-c).

The protagonists of S-D logic classify it as a thinking framework at a high level of abstraction, or a "metaidea" [23]. Although S-D logic is rooted in marketing, its scope is not limited to this specific field. Among others, the broadened view of S-D logic beyond marketing is adapted in current research on digitized service innovation $[2,6]$. In line with S-D logic, the purpose is to provide research a thinking framework that conceptualizes value creation and innovation from a service based perspective - here with focus on digitized service innovation.

The framework of digitized service innovation presented in [6] consists of three key elements: value cocreation, service ecosystem, and service platform. The latter enhances prior S-D logic understanding.

In this tripartite interplay, value co-creation is enacted within and enabled by service ecosystems that provide shared institutional logics and structures for resource integration and service exchange. However, service exchange in service ecosystems is considered inefficient without a service platform that allows actors engaged in service exchange easy access to appropriate resource bundles. Lusch and Nambisan [6] describe the service platform as a modular structure consisting of readily usable, tangible and intangible components

\footnotetext{
${ }^{2}$ To reflect its non-firm centered actor-to-actor orientation, S-D logic uses the more general term 'service beneficiary' instead of
}

(resources). A central theme of S-D logic states that indirect exchange masks the fundamental basis of exchange [15]. This underlies the conceptualization of the service platform. It plays a central role in uncovering indirect exchange of operant resources. The framework proposes to envision a service platform that facilitates the interaction of actors and resources rather than focusing on the design of a "bounded" product. This requires stepping outside the physical materiality of products and viewing how users and other actors interact. In this sense, the service platform reflects the ability of a digitized product to become the distribution mechanism for service provision [6].

Based on S-D logic, but not yet conceptually integrated with Lusch and Nambisan's framework [6], Mikusz [13] and Mikusz and Herter [9] propose the aforementioned anatomy of $\mathrm{v}-\mathrm{i}-\mathrm{c}$ with splitting the overall v-i-c into direct, indirect, and option v-i-c-all on a conceptually equal level and all can be added. Against the background of the now introduced S-D logic perspective on value creation, the three v-i-c components can be introduced by definition $[13,9]$ :

- Direct v-i-c equals S-D logic's understanding of vi-c. The value results from the direct integration of a service offering in the customer's value adding process. Direct v-i-c arises only for the customer who utilizes the offering.

- Option v-i-c results from the option to accept (use) complementary value propositions that enhance or even enable the value proposition of the service offering in that they are embedded-regardless if actually accepted (used) by the customer. Option vi-c arises only for the customer who utilizes the offering from the possibility to use "something" anytime if eventually needed in a particular context.

- Indirect v-i-c results from data as operant resource that the customer as "data co-creator" integrates in the value co-creation. The value arises for the customer who utilizes the offering and for all other actors in the value co-creation network as data as operant resource is associated with network effects: The more customers co-produce the service offering by simply using it, the higher the indirect $\mathrm{v}-\mathrm{i}-\mathrm{c}$ of the offering becomes to all customers.

Insights gained by conceptual reflections have to be translated to an empirical situation in order to become legitimized. The empirical illustrations in tables 1 and 2 are mainly based on real existing best-of offerings. Still acknowledging that in S-D logic's understanding, innovative services are not defined in terms of their new features [25], tables 1 and 2 should be read as follows: "Smart Navigation", a hypothetic connected car service

'customer' [20]. To simplify matters, the work at hand disregards this nuance and uses the common term 'customer'. 
[9], and "Cam \& Keyless", a hypothetic smart home service, are innovative digital services. Their overall v$\mathrm{i}$-c result from their direct, option and indirect $\mathrm{v}-\mathrm{i}-\mathrm{c}$. To operationalize and illustrate this, "Smart Navigation" as well as "Cam \& Keyless" are separated into three service components with certain features, whose values for the customer arise (almost) exclusively by one of the three value components of the additive v-i-c anatomy.

Table 1. Empirical Illustration: Product Sheet of "Smart Navigation" [9]

All variants of "Smart Navigation" provide a basic set of street navigation functions and setting options.

Examples: Dynamic routing, points of interest, usual 2D view, etc.

Component A: Customization (available / not av.) [High direct value-in-context]

Features: State of the art customization and ease of operation of "Smart Navigation", far beyond basic functionalities and setting options of street navigation.

Example 1: Customized display profiles with real street view, crossroads in 3D, and fully interactive screen with your preferred point of interest categories.

Example 2: Customized operation profiles with, e.g., voice-activated operation and smartphone integration

Component B: Situational services (av. / not av.) [High option value-in-context]

Features: This component automatically offers smart choices of specific services (displayed on your navigation device or smartphone), which seem to make sense in your current situation. It is always completely up to you whether you accept these proposed services either immediately or later, or prefer to ignore them completely. The services are therefore optional. In addition, these services can go beyond the scope of street navigation in a strict sense.

Example 1: Reservation of a parking space (or a charging station for an electric car) on the way to, or at the destination, once "Smart Navigation" has determined bottlenecks.

Example 2: Proposal for a seamless continuation of your journey by other means of transport (public transport, train, taxi, car-sharing, etc.) with continuing the navigation on the smartphone, once "Smart Navigation" has identified some factors that would prevent you from reaching your destination otherwise (in time) (e.g. traffic jam, insufficient range, defects).

Component C: Data co-creation (av. / not av.)

[High indirect value-in-context]

Features: Features that you and other users "coproduce" by allowing clearly defined and secure access to specific sensor data of your vehicle. Otherwise, these features would not be possible. That is, your data enhance the functionalities of "Smart Navigation" for you and for all other users (likewise, you also benefit from the other users' data transfer).

Example 1: "Real time module"-highly accurate predictions of, e.g., traffic and congestion, free parking spaces and charging stations; security alerts about approaching road sections (all in real time using your and other users' sensor data).

Example 2: "Eco driving analysis"-you compare your driving behavior with other drivers and optimize it, so you will get, e.g., fuel-saving recommendations (using your and other users' sensor data).

Table 2. Empirical Illustration: Product Sheet of "Cam \& Keyless"

All variants of "Cam \& Keyless" provide basic connectivity and basic functions of smart monitoring and keyless home access (both web-enabled).

Examples: Motion sensors trigger cam recordings, smartphone alerts and reports on monitoring events; home access via smartphone apps, etc.

Component A: Customized interconnection (available / not available)

[High direct value-in-context]

Features: State of the art customized interconnection of "Cam \& Keyless", far beyond basic connectivity and functionality of home monitoring and keyless home access.

Example 1: Customized interconnection options with other smart devices such as

smart lighting systems and smoke detectors to set customized monitoring schedules (e.g. wrong code entry for the door or smoke trigger cam recording), or

thermostats to enhance automation (e.g. automatic reduction of room temperature after leaving the house).

Example 2: Customized data storage options for access and monitoring events (e.g. storing of critical event videos in the cloud with permanent access; storing of non-critical events on the local memory card).

Component B: Situational services (av. / not av.) [High option value-in-context]

Features: This component automatically offers smart choices of specific services (e.g. displayed on your smartphone), which seem to make sense in your current situation. It is always completely up to you whether you accept these proposed services either immediately or later, or prefer to ignore them completely. The services are therefore optional. In addition, these services can go beyond the scope of home monitoring and keyless access in a strict sense.

Example 1: Smartphone alerts concerning access and monitoring events are combined with potentially helpful service offerings for the situation (e.g., in case of a questionable monitoring event you have the option to initiate a security service check or firstly broadcast live pictures to a security center, both directly via app).

Example 2: The basic functions "camera recording" and "home access via smartphone app" are available for additional, external services (e.g. indoor delivery of packages or home access for craftsmen, each via temporary digital keys without your local presence).

Component C: Data co-creation (av. / not av.)

[High indirect value-in-context]

Features: Features that you and other users "coproduce" by allowing clearly defined and secure access to specific data of your monitoring and access system. Otherwise, these features would not be 
possible. So your data enhance the functions of "Cam \& Keyless" for you and all other users (likewise, you also benefit from the other users' data transfer).

Example 1: "Better alarms module"-your smart monitoring system learns and constantly improves event detection by analyzing your and other users' data (e.g. to avoid false alarms through better detection of light reflections, shadows, etc.).

Example 2: "Better alertness module"-your smart monitoring system switches to a higher vigilance level when, e.g., critical access and monitoring events have occurred in your neighborhood (detection by using your and other users' data).

\section{Value-In-Context and Service Innovation in the Digital Age: Propositions}

Innovation is perceived with S-D logic as a process wherein all actors together seek out ways that enable them to successfully collaborate in resource integration and foster innovation instead of seeing it as a simple outcome [26]. In this sense, service innovation is defined as "the rebundling of diverse resources that create novel resources that are beneficial (i.e. value experiencing) to some actors in a given context; this almost always involves a network of actors, including the $[\ldots]$ customer" $[6]$.

Assuming that innovation is the result of recombining or rebundling existing resources, the innovation potential of a service platform is unbounded: The more actors in the co-creation network, the more shared and rebundled resources, the more innovation, the greater the benefit for all actors in the co-creation network. Each new innovation becomes a module that can be combined with other resources that, in turn, become a module for even more innovative possibilities [6]. Such network effects are generally associated with service platform mediated value co-creation and service innovation in the digital age [27].

When envisioning a service platform, all innovations are service innovations not defined in terms of features, but in line with S-D logic's emphasis on v-i-c, in terms of how they change customers' capabilities to co-create value [25]. An offering is not embedded with valueinstead, value only manifests when the offering is useful to the customer in a certain context, i.e., when he integrates it in his value adding processes (v-i-c) [26]. With this, an innovation is not required to be technological, but can also refer to an offering being used in a new way, place or time-i.e., in a different context [26]. In this way, S-D logic with its inherent customer focus moves away from perspectives traditionally rooted in technological inventions. The critical factor in this understanding is not what the product or service offering is, but how the customer can utilize it. Thus, any innovation requires changes in customer thinking, participation, and capabilities to cocreate value $[21,25,26]$.

The foregoing elaboration on service innovation already leads to propositions $1 \mathrm{a}$ and $1 \mathrm{~b}$ :

Proposition 1a: Option value-in-context reflects the potential for combinational service innovation that the customer exploits for himself by rebundling resources from complementary value propositions in his context.

Proposition 1b: Indirect value-in-context reflects the self-reinforcing potential for service innovation that the customer exploits for himself and other actors in the co-creation network by generating network effects.

Lusch and Nambisan [6] refer to three broad roles in resource integration. Depending on the nature of service exchange and the type of resource integration achieved, they differentiate between designer, ideator, and intermediary. These roles offer customers the opportunity to experience different types of value. The work at hand assumes all three roles to be fulfilled by customers in co-creating innovative digital services.

The designer role reflects the capability of customers to mix and match existing resources to configure service offerings for themselves. This signifies the need for other actors in the service ecosystem (especially service platform leader and complementors) to present their complementary value propositions in a way that facilitates such resource integration. The service platform serves as a venue for service innovation in this regard because it enables actors in the service ecosystem to easily present or discover novel complementary value propositions that may lead to innovative, scalable service offerings [6].

From this point of view, service innovation can also arise through the customer who seeks and builds his own best service experience from the available complementary value propositions. With combinatorial and generative innovations, the boundary of a service offering is unknowable and the offering remains incomplete $[1,28]$ until the customer as designer (re)bundled the available complementary value propositions for his purposes in his context.

Proposition 2a: Option value-in-context reflects the opportunity of customers to experience value from their role as designers.

The ideator role reflects the capability of customers to bring knowledge about their needs and unique context to the value co-creation that then can be integrated with knowledge about how all customers use existing service offerings in order to innovate. This role emphasizes the need to support knowledge conversion within value cocreation and to enable sharing of the knowledge output with all actors in the service ecosystem. All actors are resource integrators and thus all actors are potential innovators of value, i.e. ideators [6]. 
As innovation with digitally enabled service offerings relies not only on algorithms but also on the crowds that generate the data [2], the ideator role is not less important in this context. Instead, the transformation of the customer to an ideator as an active and vital, if not the most important co-creating actor, goes hand in hand with the fact that customers' (sensor) data need to be turned into a main operant resource. (Sensor) data processed in accordance with the DataInformation-Knowledge-Pyramid eventually represents the aforementioned knowledge that the customer as ideator brings to value co-creation (e.g. needs, behavior, preferences). Hence, the customer is not a passive actor, but an active resource integrator and co-creator of value - a "data co-creator" or more precisely a "knowledge co-creator" in a network of actors. Recent research on customer participation clearly indicates that this kind of customer participation offers not only tangible benefits, but is intrinsically attractive to customers who derive enjoyment simply from their experience of participation in service delivery $[29,11]$.

Proposition 2b-I: Indirect value-in-context reflects the opportunity of customers to experience value from their role as ideators.

The intermediary role reflects the capability of customers to cross-pollinate knowledge across multiple service ecosystems and to serve as intermediaries in service innovation. In this role, the customer helps to make nonobvious connections across service ecosystems in a way that provides value for himself and others. The intermediary role emphasizes the need to facilitate the export and import of knowledge across service ecosystem boundaries and the ability to explore and discover nonobvious connections among the diverse resources, especially the operant ones [6]. The work at hand interprets the intermediary role as widening of the ideator role. This role even more emphasizes the customers' (sensor) data as a main operant resource.

Proposition 2b-II: Indirect value-in-context reflects the opportunity of customers to experience value from their role as intermediaries.

As previously mentioned, the definition of the service platform refers in line with S-D logic to two types of resources - operand and operant. Lusch and Nambisan [6] seize on this distinction and emphasize a dual role of the service platform's digital components: First, as operand resource and thus facilitator or enabler in service innovation; second, as operant resource and thus initiator in service innovation [6,30].

In the former role, digital components of a service platform enable the sharing and integrating of resources. Actors are supported in searching for appropriate resources and bundling them within and across service platforms in the given context. To promote service innovation, actors in the service ecosystem must gain access to suitable combinations of operant resources that match the problem context. Hence, digital components incorporated in the service platform seen as operand resource increase the level of resource density in the service platform. Maximum resource density occurs when the best combination of resources can be mobilized for a particular situation [6]. Here, the service platform at its best enables to dynamically construct and disseminate value propositions, or in other words, to dynamically assemble service offerings from a large number of complementary value propositions.

Proposition 3a: Option value-in-context reflects the role of the service platform's digital components as operand resource and thus facilitator or enabler in service innovation.

Seen as operant resource, digital components of the service platform become an active part of the service ecosystem that can independently initiate service exchange and service innovation [6] (e.g. software agents). This involves seeking out and pursuing unique resource integration opportunities. Such a role underscores how the increasing extent of digital components in the service platform can unleash generativity and create novel opportunities for resource integration and thus service innovation $[6,30]$.

The service platform's digital components as operant resource initiate service innovation based on the ability to unlock the full value of data, in turn understood as operant resource. Again, network effects and the unbounded innovation potential of a service platform play a central role: The more co-creators in the network, the more data on that digital components in the service platform can independently initiate service exchange and service innovation, the more innovation, the greater the benefit for all co-creators in the network.

Proposition 3b: Indirect value-in-context reflects the role of the service platform's digital components as operant resource and thus initiator in service innovation.

\section{Value-In-Context and Service Innovation in the Digital Age: Conjoint Analysis}

In this chapter, the $\mathrm{v}-\mathrm{i}-\mathrm{c}$ anatomy is empirically validated with two conjoint analyses (CA). By showing that both newly introduced components of $\mathrm{v}-\mathrm{i}-\mathrm{c}$ are important factors involved in the choice process for innovative digital services, the aim is to support the assumption on that the v-i-c anatomy is proposed in [9] and [13]: The option and indirect v-i-c components are also decisive factors in customers' perceptions of $\mathrm{v}-\mathrm{i}-\mathrm{c}$ and substantially contribute to service experience with innovative digital services-implicating their conceptual separation. 
CA is a multivariate method developed specifically to understand how respondents shape preferences for any type of object, e.g., products or service offerings. It is based on the simple premise that customers evaluate value of an object, real or hypothetical, by combining separate amounts of value provided by each factor (component, feature, attribute, etc.). By constructing specific combinations of the factors, i.e. object profiles, the researcher can reveal a respondent's preference structure. The preference structure depicts how important each factor is in the overall decision, as well as how differing levels within a factor influence the overall preference (utility value) [31].

CA is able to reveal the relative value contributions of the three $\mathrm{v}-\mathrm{i}-\mathrm{c}$ components (factors) to the evaluation of the overall v-i-c of a service offering (object). Given the small number of factors (three) and due to the emphasis on a throughout understanding of the preference structure, the author has regarded the traditional CA as suitable in terms of response burden on the respondents and the depth of information portrayed. The traditional CA is widely used when the number of factors is around six or less. The small number of factors obviates the need for the adaptive or hybrid CA. Arguments against the choice-based CA are the fact that this third common variant of CA does not allow the estimation of part-worths on the individual level, and no need for a no-choice-option.

Using the traditional CA with the chosen design, respondents rank object profiles as stimuli that represent products or services with predefined factors and factor levels. The ranking can then be mathematically decomposed, delivering utility values (part-worths) for each factor level and the relative importance of each factor. The latter is represented by the difference between the highest and lowest values, divided by the sum of the ranges across all factors. Factors with a larger range for their part-worths have a greater impact on the calculated utility values and thus are more important [31].

The analyses were conducted based on "Smart Navigation" (1) and "Cam \& Keyless" (2) services shown in tables 1 and 2 (a subset of the database of CA (1) is used in [9] in order to investigate how customers evaluate value propositions of connected car services). The overall v-i-c of the value propositions of both service offerings result from their direct, option and indirect v-i-c, i.e. from their three components A, B, and $\mathrm{C}$ - each with features, whose values for the customer arise (almost) exclusively by one of the three $\mathrm{v}-\mathrm{i}-\mathrm{c}$ components. With "available / not av.", there is (a) an equal number of two levels the factor (b) with same extreme end-points - in order to (a) avoid the number of levels effect and (b) decrease task complexity [31]. With these eight combinations in total (two levels the factor and three factors), a full factorial design could be employed: All respondents evaluated all possible profiles that were described in terms of all factors without information overload. Thereby, the respondents faced a large number of trade-offs regarding availability of the components A, B, and C. All in all, both CA come up with an orthogonal and balanced profile design [31].

The participants were asked to sort the eight variants of "Smart Navigation" and "Cam \& Keyless" (profiles) respectively, according to the usefulness for them. So preferences were evaluated by asking respondents to rank-order the profiles in terms of preference and not to rate each combination on a preference scale. This method is likely to be more reliable because ranking is easier than rating for a reasonably small number of profiles (20 or fewer) [31], as in this case.

The surveys were set up using the online survey software questback EFS Survey. To begin with, the context of the experiment and all factors and factor levels were explained to ensure that participants clearly understand the stimuli. Then, participants were asked to rank the variants of "Smart Navigation" and "Cam \& Keyless" (profiles) respectively. They were also able to rank profiles equivalent and adjust the ranking at any time. The profiles were described by means of combined visual and textual representations and appeared in random order.

The surveys were conducted in October 2015 and April 2016. Prior to this, small-scale pre-studies were performed to ensure that the measures are clearly understandable and represent reasonable alternatives when formed into profiles. Invitations to the surveys were published in issue-specific online forums, interest groups in social media, and among IS students. The requirements on the characteristics of the population of interest were, among others, familiarity with main features and capabilities of state-of-the-art connected cars and smart homes respectively.

104 (1) / 101 (2) participants filled out the questionnaire with appropriate respondent effort. This initial data base was subject of further reliability tests at the level of input judgments of the respondents [32]: attention check, self-evaluation of understanding of the components, and self-evaluation of the abovementioned familiarity. 13 (1) / 18 (2) datasets were removed due to low reliability.

The obtained rank-order preference measures were estimated with MANOVA using the CA module of XLSTAT. MANOVA is among the most popular and best known methods in the class of algorithms designed for an ordinal-scaled dependent variable [31, 32]. The estimates were validated using the adjusted $\mathrm{R}^{2}$ value that is interpreted as the proportion of the variability of the dependent variable explained by the model. It is a correction to the $\mathrm{R}^{2}$ since it compensates lower degrees 
of freedom $[31,32]$ that are given in this case. $0(1) / 3$ (2) datasets were removed due to low validity.

All remaining part-worth patterns were reviewed in order to identify any that may reflect reversals. Reversals represent illogical patterns in the overall preference structure as measured by the part-worths [31]. Here, negative part-worths for Customization (1)/ Customized interconnection (2) (components A) and Situational services (components B) are considered illogical and thus reversals, while parth-worths of Data co-creation (components C) can be either negative or positive. 8 (1) / 2 (2) reversals were identified and removed.

At the end, the adjusted samples contain 83 (1) / 78 (2) datasets that were subject of analysis on the aggregated level. The sample size and quality is sufficient for the present purpose. The demographics of the participants in both surveys are roughly similar: About two thirds of the survey participants are aged between 18 and 29; about one third between 30 and 70 .

Table 3 shows the aggregated relative importances of the v-i-c components in both surveys. From the mean values, we can infer with relatively high certainty that option as well as indirect $\mathrm{v}-\mathrm{i}-\mathrm{c}$ are decisive factors for customers' perceptions of value. All v-i-c components contribute to the overall v-i-c nearly in equal shares except for indirect v-i-c in case of "Cam \& Keyless", which, nevertheless, with $19 \%$ still sufficiently supports the arguments.

Table 3. Aggregated relative importances of the value-in-context components

\begin{tabular}{|c|c|c|c|}
\hline CA & Component & Mean & $\begin{array}{l}\text { Std. } \\
\text { dev. }\end{array}$ \\
\hline \multirow{3}{*}{$\begin{array}{c}\text { Smart } \\
\text { Navigation } \\
\text { (connected } \\
\text { car } \\
\text { domain) } \\
\mathrm{N}=83\end{array}$} & $\begin{array}{l}\text { Direct value-in-context } \\
\text { (A: Customization) }\end{array}$ & $35 \%$ & 25 \\
\hline & $\begin{array}{l}\text { Option value-in-context } \\
\text { (B: Situational services) }\end{array}$ & $32 \%$ & 20 \\
\hline & $\begin{array}{l}\text { Indirect value-in-context } \\
\text { (C: Data co-creation) }\end{array}$ & $33 \%$ & 26 \\
\hline \multirow{3}{*}{$\begin{array}{c}\text { Cam \& } \\
\text { Keyless } \\
\text { (smart } \\
\text { home } \\
\text { domain) } \\
\mathrm{N}=78\end{array}$} & $\begin{array}{c}\text { Direct value-in-context } \\
\text { (A: Customized interconnect.) }\end{array}$ & $49 \%$ & 18 \\
\hline & $\begin{array}{l}\text { Option value-in-context } \\
\text { (B: Situational services) }\end{array}$ & $32 \%$ & 17 \\
\hline & $\begin{array}{l}\text { Indirect value-in-context } \\
\text { (C: Data co-creation) }\end{array}$ & $19 \%$ & 15 \\
\hline
\end{tabular}

The upper parts of figures 1 and 2 compare the relative importance of direct $\mathrm{v}-\mathrm{i}-\mathrm{c}$ to indirect and option $\mathrm{v}$-i-c. This is done to avoid arguing with a "pseudohigh" relative importance of both newly introduced components: high relative importance of option v-i-c exclusively at the expense of high relative importance of indirect v-i-c and vice versa. The lower parts of figures 1 and 2 show if the respective $\mathrm{v}-\mathrm{i}-\mathrm{c}$ component is associated with positive value (has a benefit), negative value (has no benefit), or is indifferent for the participants. For example (illustrated in figure 1), of those $54 \%$ of participants who consider indirect v-i-c as equal or even more important than direct v-i-c, 91\% perceive the value of indirect $\mathrm{v}-\mathrm{i}-\mathrm{c}$ as positive. This means that they prefer a service with high indirect v-i-c (Data co-creation component), while $7 \%$ perceive the value of high indirect $\mathrm{v}-\mathrm{i}-\mathrm{c}$ as negative.

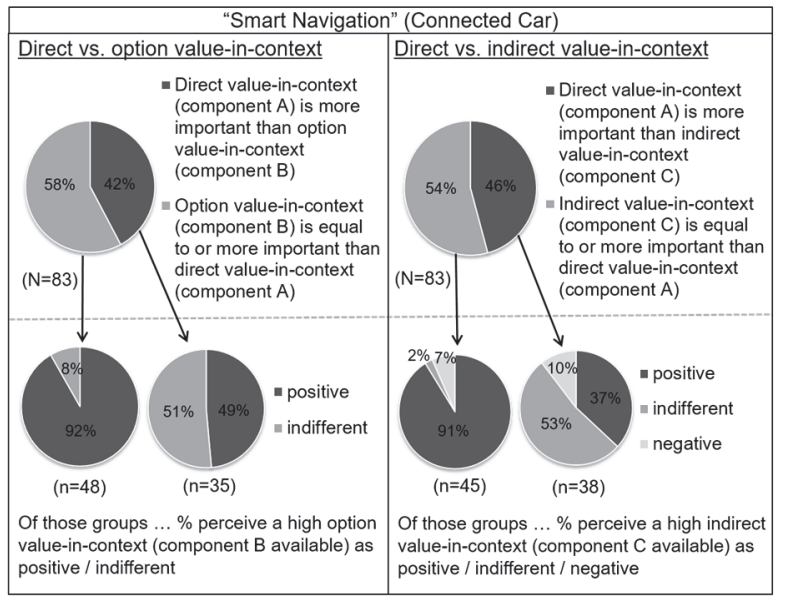

Figure 1. Indirect and option value-in-context compared to direct v-i-c in case of "Smart Navigation"

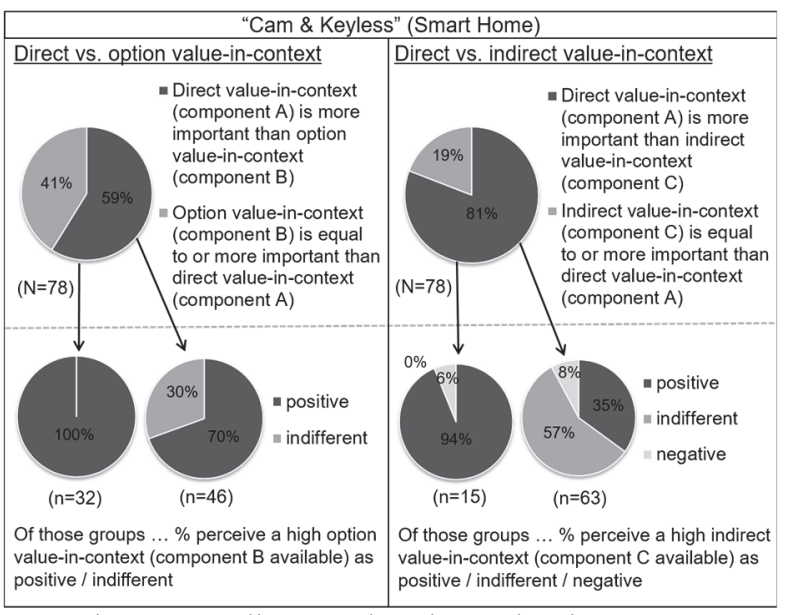

Figure 2. Indirect and option value-in-context compared to direct v-i-c in case of "Cam \& Keyless"

\section{Conclusion}

The increasingly complex service context with the convergence of physical products, digitalization, and service offerings results, among others, in the need for research on an adequate understanding of the perceived value of innovative digital services. This article continues the work presented in [9] and [13] that makes the first move in this regard-conceptualizing the 
perceived value of innovative digital services on the consequence level as a tripartite, additive value-incontext ( $\mathrm{v}-\mathrm{i}-\mathrm{c})$ anatomy: The overall $\mathrm{v}-\mathrm{i}-\mathrm{c}$ equals the sum of three value components that may be addeddirect v-i-c (S-D logic's construct) [e.g. 6, 14, 15], indirect $\mathrm{v}-\mathrm{i}-\mathrm{c}$ (newly introduced), and option $\mathrm{v}-\mathrm{i}-\mathrm{c}$ (newly introduced).

This article closes two research gaps on the conceptual and empirical level respectively, and thus contributes to a more detailed and differentiated understanding of $\mathrm{v}-\mathrm{i}-\mathrm{c}$ with innovative digital services.

First, chapter 3 presents a logically interconnected set of propositions that link both newly introduced v-i-c components to S-D logic's main concepts of service innovation. That way, the propositions clarify the concepts of option and indirect $\mathrm{v}-\mathrm{i}-\mathrm{c}$, which have not yet been seamlessly integrated into S-D logic's thinking framework on the conceptual level. Chapter 3 advances the understanding of how v-i-c arises in service platform mediated value co-creation by revealing the complex interplay of v-i-c, service innovation, the customers' cocreation activities (roles), and the service platform's digital components.

Second, the v-i-c anatomy is empirically validated with two conjoint analyses (CA). As shown in chapter 4 , both newly introduced components of $\mathrm{v}$-i-c indeed are decisive factors for customers' perceptions of value with innovative digital services. However, the general critique on the traditional CA with the chosen design by nature applies to both surveys: To some extent, oversimplification of reality; limitations can result from the low number of factors and factor levels; it may be difficult for respondents to evaluate profiles online. Despite these drawbacks that were resolved best possible, the author deems the traditional CA the most appropriate evaluation approach for the present purpose.

The results of both CA (and also implicitly the propositions in chapter 3) underlay the need for a conceptual separation of the option and indirect v-i-c components. As analogous to measuring-what we can conceptually separate largely determines what we are able to study. Conceptual separations of constructs can break dominant frames, inform thinking with new perspectives, and direct the attention to certain aspects-provided that not too much complexity is introduced that impedes the explanatory power. Furthermore, the tripartite $\mathrm{v}-\mathrm{i}-\mathrm{c}$ anatomy gets S-D logic's understanding of value as v-i-c closer to the IS phenomenon of innovative digital services. The empirical illustration and operationalization of the proposed v-i-c anatomy that has also built the basis for both CA provides an example of how the constructs can be translated into a real situation.

The anatomy of $\mathrm{v}-\mathrm{i}-\mathrm{c}$ that is enhanced here may help in practice to acquire and deepen the understanding of how innovative digital services create value for customers. With digitized, intelligent products that have become platforms for service provision, companies are able to form new kinds of relationships with customers. Such an understanding allows better positioning of offerings and more effective communication of their value to customers. Companies can segment their markets in more sophisticated ways, and tailor the convergent and highly integrated, digitally enabled product-service bundles accordingly [5]. Furthermore, the v-i-c components can serve as building blocks for the design of novel and unique service offerings, stimulating service and business model innovation.

Further conceptual research could strive towards a closer connection of this S-D logic driven research and management research on technology platforms [e.g. 27], especially to refine the concept of indirect v-i-c. Due to the utmost importance of network effects in service platform mediated value co-creation, this seems fruitful and could help towards a better understanding of value co-creation and service innovation in the digital age. To advance the concept of option $\mathrm{v}-\mathrm{i}-\mathrm{c}$, the issue of complementary value propositions is worthy of discussion in the light of S-D logic's notion of a value proposition being not successful when an actor did not reply to (used) it [e.g. 33]. Option v-i-c shows that, when considering platform mediated value co-creation, complementary value propositions may indeed be valuable for the customer even if he did not reply to (used) them. That is the reason why this kind of value propositions hold high option value-in-context. Such a discussion could contribute back to S-D logic as the reference discipline of the v-i-c anatomy [34].

Further empirical research could test the v-i-c anatomy in other domains and conduct a deeper analysis at the aggregated level. The most relevant technique of analysis for aggregation is cluster analysis. Clustering is quite useful in forming subgroups of respondents for analysis at an aggregated level [31]. This article abstained from a cluster analysis so far. In addition, more research effort is required in order to empirically investigate how the three $\mathrm{v}$-i-c components interact. The additive model may be an oversimplification and needs further elaboration.

In building theory, the goal is to get propositions to the point where their claims can be, or are, fully tested empirically, so completing the link between theory and empirical evidence [17]. Yet, not each and every proposition from chapter 3 is tested, but the overall assumption that the option and indirect $\mathrm{v}-\mathrm{i}-\mathrm{c}$ components are also decisive factors in customers' perceptions of value (-in-context) and so substantially contribute to service experience with innovative digital services. Therefore, there is need for research that closer connects conceptual insights and empirical evidence. 


\section{Acknowledgments}

I thank Tobias Herter for help in conducting the online surveys.

\section{References}

[1] Y. Yoo, R. J. Boland, K. Lyytinen and A. Majchrzak, "Organizing for Innovation in the Digitized World," Organization Science, vol. 23, pp. 1398-1408, 2012.

[2] M. Barrett, E. Davidson, J. Prabhu and S. L. Vargo, "Service Innovation in the Digital Age: Key Contributions and Future Directions," MIS Q., vol. 39, pp. 135-154, 2015. [3] R. T. Rust, "If Everything Is Service, Why Is This Happening Now and What Difference Does It Make?," Journal of Marketing, vol. 68, pp. 23-24, 2004.

[4] M. E. Porter and J. E. Heppelmann, "How Smart, Connected Products Are Transforming Companies," Harvard Business Review, vol. 93, pp. 53-71, 2015.

[5] M. E. Porter and J. E. Heppelmann, "How Smart, Connected Products Are Transforming Competition," Harvard Business Review, vol. 92, pp. 65-88, 2014.

[6] R. F. Lusch and S. Nambisan, "Service Innovation: A Service-Dominant Logic Perspective," MIS Quarterly, vol. 39, pp. 155-175, 2015.

[7] A. L. Ostrom, A. Parasuraman, D. E. Bowen, L. Patricio and C. A. Voss, "Service Research Priorities in a Rapidly Changing Context," Journal of Service Research, vol. 18, pp. 127-159, 2015.

[8] R. T. Rust and M.-H. Huang, "The Service Revolution and the Transformation of Marketing Science," Marketing Science, vol. 33, pp. 206-221, 2014.

[9] M. Mikusz and T. Herter, "How Do Consumers Evaluate Value Propositions of Connected Car Services?,"

Proceedings of the $22^{\text {nd }}$ Americas Conference on Information Systems, San Diego, 2016.

[10] M. B. Holbrook, "Consumption Experience, Customer Value, and Subjective Personal Introspection: An Illustrative Photographic Essay," Journal of Business Research, vol. 59, pp. 714-725, 2006.

[11] B. Dong, "How a Customer Participates Matters: "I am Producing" versus "I am Designing"," Journal of Services Marketing, vol. 29, pp. 498-510, 2015.

[12] S. A. Rijsdijk and E. J. Hultink, "How Today's Consumers Perceive Tomorrow's Smart Products," Journal of Product Innovation Management, vol. 26, pp. 24-42, 2009. [13] M. Mikusz, "Cyber-Physical Systems as Service Systems: Implications for S-D Logic," Proceedings of the 2015 Naples Forum on Service, 2015.

[14] S. L. Vargo and R. F. Lusch, "Evolving to a new dominant logic for marketing," Journal of Marketing, vol. 68, pp. 1-17, 2004.

[15] S. L. Vargo and R. F. Lusch, "Service-dominant logic: continuing the evolution," Journal of the Academy of Marketing Science, vol. 36, pp. 1-10, 2008.

[16] L. Hein, K. van Koppen, R. S. de Groot and E. C. van Ierland, "Spatial Scales, Stakeholders and the Valuation of Ecosystems Services," Ecological Economics, vol. 57, pp. 209-228, 2006.
[17] N. R. Hassan and P. B. Lowry, "Seeking Middle-Range Theories in Information Systems Research," Proceedings of the 36. Int. Conf. on Information Systems, Fort Worth, 2015. [18] Y. Yoo, "The Tables Have Turned: How Can the Information Systems Field Contribute to Technology and Innovation Management Research?," J. of the Association for Information Systems, vol. 14, pp. 227-236, 2013.

[19] A. Majchrzak and M. L. Markus, "Technology Affordances and Constraints in Management Information Systems (MIS)," Encyclopedia of Management Theory, E. Kessler (ed.), Thousand Oaks, CA: Sage, pp. 832-836, 2013. [20] S. L. Vargo and R. F. Lusch, "Institutions and axioms: an extension and update of service-dominant logic," Academy Marketing Science, vol. 44, pp. 5-23, 2016. [21] S. L. Vargo, R. F. Lusch, M. A. Akaka and Y. He, "The Service-Dominant Logic of Marketing. Review and Assessment," Review of Marketing Research, vol. 6, pp. 125-167, 2010.

[22] R. F. Lusch, S. L. Vargo and M. Tanniru, "Service, value networks and learning," Journal of the Academy of Marketing Science, vol. 38, pp. 19-31, 2010.

[23] R. F. Lusch and S. L. Vargo, "Service-Dominant Logic: Premises, Perspectives, Possibilities," 2nd Edition, Cambridge: Cambridge University Press, 2014.

[24] S. L. Vargo, P. P. Maglio and M. A. Akaka, "On value and value co-creation: A service systems and service logic perspective," European Managem. J., 26, pp. 145-152, 2008. [25] S. Michel, S. W. Brown and A. S. Gallan, "An expanded and strategic view of discontinuous innovations: deploying a service-dominant logic," Journal of the Academy of Marketing Science, vol. 36, pp. 54-66, 2008.

[26] C. Mele, M. Colurico and T. Russo-Spena, "Research Traditions of Innovation," Managing Service Quality, vol. 24, pp. 612-642, 2014.

[27] A. Gawer, "Bridging Differing Perspectives on Technological Platforms: Toward an Integrative Framework,” Research Policy, vol. 43, pp. 1239-1249, 2014. [28] Y. Yoo, O. Henfridsson and K. Lyytinen, "The new Organizing Logic of Digital Innovation: An Agenda for Information Systems Research," Information System Research, vol. 21, pp. 724-735, 2010.

[29] C. K. Yim, K. W. Chan and S. S. K. Lam, "Do Customers and Employees Enjoy Service Participation? Synergistic Effects of Self- and Other-Efficacy," Journal of Marketing, vol. 76, pp. 121-140, 2012.

[30] S. Nambisan, "Information Technology and Product/Service Innovation: A Brief Assessment and Some Suggestions for Future Research,” Journal of the Association for Information Systems, vol. 14, pp. 215-226, 2013.

[31] J. F. Hair, W. C. Black, B. J. Babin and R. E. Anderson, "Multivariate Data Analysis. A global perspective," 7th. Edition, Upper Saddle River: Pearson, 2010.

[32] P. E. Green and V. Srinivasan, "Conjoint Analysis in Consumer Research: Issues and Outlook," Journal of Consumer Research, vol. 5, pp. 103-123, 1978.

[33] J. D. Chandler and R. F. Lusch, "Service Systems: A Broadened Framework and Research Agenda on Value Propositions, Engagement, and Service Experience," Journal of Service Research, vol. 18, pp. 6-22, 2015.

[34] V. Grover and K. Lyytinen, "New State of Play in Information Systems Research: The Push to the Edges," MIS Quarterly, vol. 39, pp. 271-296, 2015. 